\author{
JUAN PABLO ARANDA VARGAS* \\ JORGE MEDINA DELGADILLO*** \\ VÍCTOR MANUEL TOPETE CAMARENA***
}

\title{
INDEFINIBILIDAD, CIENCIA Y METAFÍSICA: EL CASO DE LA PERSONALIDAD ONTOLÓGICA DEL FETO
}

Fecha de recepción: 04 de enero de 2020

Fecha de aceptación: 03 de marzo de 2020

RESUMEN: Confrontados con la pregunta sobre si el feto debe ser considerado como persona, el presente estudio propone tres formas de aproximar la noción de «persona» - gramatical, geométrica y metafísica - y argumenta que la personalidad ontológica del feto representa un caso límite que exige adoptar definiciones asintóticas, formuladas en gerundio y apoyadas en argumentos metafísicos. Respecto del proceso de gestación, la ciencia muestra (a) que dicho proceso es ininterrumpido; (b) la convivencia de dos organismos — feto y madre- independientes e íntimamente relacionados; y (c) que existe evidencia que sugiere la capacidad de sentir dolor del feto. Finalmente, recuperamos una concepción teológica de la persona, afirmando que tratar al feto como si fuera una persona va más allá del cálculo prudencial de daños y supone una actitud frente al «misterio» en tanto pregunta que desborda lo científico y se anida en el centro mismo de la existencia humana.

PALABRAS CLAVE: persona; feto; definición; misterio; problema; aborto.

* Universidad Popular Autónoma del Estado de Puebla: juanpablo.aranda@upaep.mx; ORCID: https://orcid.org/0000-0003-2691-2588

** Universidad Popular Autónoma del Estado de Puebla: jorge.medina@upaep.mx

**** Hospital Ángeles de Puebla: victorwtops@gmail.com 


\section{Indefinability, Science, and Metaphysics: The Case of the Fetus' Ontological Personality}

ABSTRACT: Faced with the question about whether the fetus should be deemed a human person, this work discusses three ways of approaching the idea of the "person» - grammatical, geometrical, and metaphysical—arguing that the fetus' ontological personality is an edge case that forces us to use asymptotic definitions, formulated in gerund, and leaning on metaphysical claims. Scientific evidence regarding the fetus' gestation shows $(a)$ that this process is uninterrupted; $(b)$ the coexistence between two independents, but nonetheless intimately related organisms; and (c) that there is evidence suggesting the fetus' capacity to feel pain. Finally, we retrieve $a$ theological conception of the person, affirming that treating the fetus as if she is a person goes beyond a prudential calculus of damage, and rather implies taking a stand before the "mystery», understood as a question that overflows the realm of the scientific, locating itself at the very core of human existence.

KEY WORDS: person; fetus; definition; mystery; problem; abortion.

«Quid tam tuum quam tu, quid tam non tuum quam tu». SAN Agustín

Frente a la plétora de perspectivas a partir de las cuales el aborto es analizado, la pregunta por el estatus ontológico del feto, es decir, la pregunta sobre si el feto debe considerarse o no una "persona», posee una especial relevancia. La centralidad de la pregunta deriva del hecho de que, de ser posible una respuesta definitiva a esta pregunta, la relevancia de todas las demás consideraciones consecuentemente disminuiría, o desaparecería por completo. Pues, si el feto es una persona humana, entonces se sigue, necesariamente, su derecho a recibir la protección que las leyes extienden a todo ser humano ${ }^{1}$.

${ }^{1}$ La opinión del juez norteamericano, Antonin Scalia, es ilustrativa a este respecto: «Creo que cuando la Constitución dice que las personas tienen igual derecho a la protección de las leyes, claramente se refiere a personas que andan en el mundo [walking-around persons]» (Joshua J. Craddock. "Protecting Prenatal Persons: Does the Fourteenth Amendment Prohibit Abortion?". Harvard Journal of Law \& Public Policy 40-2 (2017): 542. Todas las traducciones de fuentes anglosajonas son nuestras). Scalia fuerza una distinción ontológica entre el feto y la persona fuera del útero, considerando al primero como «no-persona» o «cuasi-persona», y por ende negándole 
La centralidad del estatus ontológico del feto puede observarse en la crítica que Simone de Beauvoir hace a la Iglesia católica, acusando a esta última - que defiende la idea de que el embrión «debe ser tratado como una persona desde la concepción $»^{2}-$ de «dotar de un alma al embrión» ${ }^{3}$, contradiciendo la máxima de derecho romano: "partus antequam edatur mulieris portio est vel viscerum» («antes de nacer, el niño es una porción de la mujer, una especie de víscera»).

Mientras algunos trabajos han estudiado la personalidad del feto argumentando que este, en tanto persona en potencia, debe gozar de los mismos derechos que las personas "propiamente dichas» ${ }^{4}$, otros ofrecen definiciones de la persona humana que problematizan la inclusión o no del feto en la categoría de "persona». Así, por ejemplo, Ossorio define a la persona como «un individuo cuya historia es, paradigmáticamente, una historia de acción deliberada» $»^{5}$, estableciendo la capacidad de agencia como el elemento distintivo de la personalidad. Charles Taylor, por su parte, combina las características de agencia y reflexividad, definiendo a la persona como «un ser que tiene un sentido de sí mismo ( $a$ sense of self), una noción del futuro y el pasado, que puede tener valores, tomar decisiones; en suma, que puede adoptar un plan de vida ${ }^{6}$. Peter Singer, finalmente, la define como «un ser racional y autoconsciente que tiene consciencia de sí como una entidad distinta con un pasado y futuro» ${ }^{7}$.

Pero, ¿qué hace a una definición más atinada que las demás? ¿Bajo qué estándares es posible evaluar distintas perspectivas sobre la persona

las protecciones constitucionales de que goza toda persona. Esta distinción es, como se verá abajo, arbitraria o, en lenguaje schmittiano, no remite más que a la capacidad decisionista del poder político para definir las fronteras de la ley.

2 Iglesia Católica. Catecismo de la Iglesia Católica. Ciudad del Vaticano: Libreria Editrice Vaticana, 1997, §2274. Énfasis nuestro.

3 Simone de Beauvoir. El Segundo Sexo. México: Penguin Random House, 2012, 112.

${ }^{4}$ Charles Camosy. "Common Ground on Surgical Abortion? -Engaging Peter Singer on the Moral Status of Potential Persons". Journal of Medicine and Philosophy 33 (2009): 588; cf. Don Marquis. "Abortion and the Beginning and End of Human Life”. Journal of Law, Medicine \& Ethics 34-1 (2006): 17.

${ }^{5}$ Raymond Bergner. "What is a Person? What is the Self? Formulations for a Science of Psychology". Journal of Theoretical and Philosophical Psychology 37- 2 (2017): 78.

6 Charles Taylor. "The Concept of a Person". Philosophical Arguments I. Cambridge: Cambridge University Press, 1985, 97.

7 Camosy. "Common Ground", 579. 
humana? ¿Es posible arribar a una definición adecuada de la persona humana a través de la observación o, por el contrario, excede este concepto, ineluctablemente, la dimensión fenoménica? Y si la excede, ¿cómo justificar cualquier definición cuando se comprende que todo esfuerzo por definir a la persona humana necesita apoyarse en distinciones metafísicas?

El presente estudio reflexiona sobre las diversas formas de entender el acto de "definir» cuando aquello definido es la persona humana. Al respecto, proponemos tres formas distintas de aproximarse a la noción de "persona» - gramatical, geométrica y metafísica- puntualizando las dificultades con que se encuentra todo esfuerzo de definir a la persona humana y, sobre todo, el caso límite de la personalidad del feto.

Con este marco teórico en mente, analizamos los datos que arroja la ciencia sobre la gestación del feto, a fin de mostrar que dicho proceso es ininterrumpido, es decir, que en el mismo no es posible identificar «rupturas»; que, desde su gestación, debemos hablar de dos organismos — feto y madre - independientes y, no obstante, íntimamente relacionados; y que la evidencia respecto del desarrollo fetal sugiere la posibilidad de que este sufra, esto es, que sienta dolor.

Finalmente, recuperamos la concepción teológica de la persona desarrollada por Joseph Ratzinger, proponiéndola como una aproximación, entre otras, al problema de la definición de "persona». Analizamos, asimismo, la idea, defendida por Markus Mühling y David Gilland, de que el pluralismo democrático exige defender un «velo de ignorancia» cuando se trata del estatus ontológico del feto, que en la práctica exige actuar como si (als ob) el feto fuera una persona, a fin de evitar cometer un daño mayor, proponiendo que esta propuesta puede enriquecerse introduciendo la diferencia entre «problema» $\mathrm{y}$ «misterio» hecha por Gabriel Marcel.

\section{EL PROBLEMA DE LA DEFINICIÓN}

Que una condición necesaria de todo conocer sea la formulación de definiciones es claro para cualquiera que haya hojeado una obra filosófica o científica. El acto de definir puede entenderse como el esfuerzo encaminado a generar discriminaciones entre elementos, haciendo comparaciones en términos de cercanía/lejanía, similitud/diferencia, continuidad/ ruptura, etc., a través de las cuales emergen delimitaciones entre conjuntos 
de elementos. Así, por ejemplo, la ciencia distingue entre animales que poseen un exoesqueleto y aquellos que tienen un endoesqueleto; entre animales nacidos de huevo y animales nacidos del vientre materno; entre tumores cancerosos y no cancerosos; entre figuras con tres o cuatro lados, etc. Esta forma de definir, propia de la ciencia, aproxima el objeto a partir del estudio cuidadoso de las características o accidentes compartidos o no por determinados elementos.

Esta estrategia, que podemos definir como constructivista, no pregunta, empero, por la «cosa en sí», sino que la aproxima a través de sus principales características, estableciendo las distancias que existen entre estas y aquellas propias de otros elementos. Si nuestro esfuerzo por definir, por el contrario, busca indagar aquello que hace que algo sea lo que es, entonces no se trata ya de una aproximación a partir de accidentes, sino del establecimiento puntual, esencialista, de aquello que se estudia. Cuando, por ejemplo, el cristianismo define a la persona humana como imago Dei (Gn 1,27), la definición no busca una aproximación, sino más bien traer al frente la peculiar característica que hace que los seres humanos sean lo que son, esto es, su esencia.

La estrategia constructivista puede describirse en términos geométricos, dependiendo del grado de exactitud que busquemos generar. Cuando una definición busca identificar los elementos a través de los cuales es posible cercar o delimitar con precisión un grupo de elementos, entonces hablamos de una definición cerrada. Cuando, por el contrario, una definición reconoce que existen casos límite que ponen a prueba la capacidad discriminativa de la definición, dificultando o, inclusive, imposibilitando una decisión final sobre la pertenencia o no de un elemento a la definición, entonces hablamos de una definición asintótica (figura 1). 

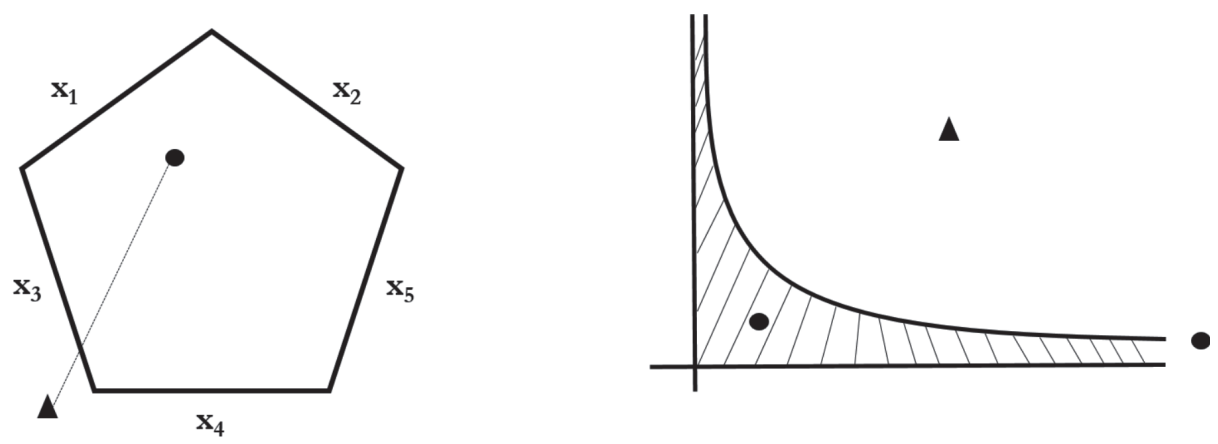

Figura 1. Definiciones cerradas y definiciones asintóticas

En una definición cerrada compuesta, por ejemplo, de cinco elementos $\left(x_{1}, x_{2}, x_{3}, x_{4}, x_{5}\right)$, es posible distinguir con claridad entre elementos fuera y dentro de la definición. En las definiciones asintóticas, en cambio, si bien existen razones suficientes para distinguir entre elementos fuera y dentro de la definición - gráficamente, dentro y fuera del área sombreada-se reconoce que ciertos elementos llevan la definición a una zona de indeterminación, es decir, plantean preguntas irresolubles.

En este punto es posible generar una primera hipótesis: la pregunta por la personalidad del feto es indefinible a través de una definición cerrada y, por consiguiente, solo a partir de una definición asintótica, donde el feto ocupa un caso límite, podemos comenzar a pensar el problema.

Para entender la imposibilidad de las definiciones cerradas cuando está en juego la pregunta por la persona humana, podemos introducir una segunda estrategia de definición. Si pensamos en términos gramaticales, podemos decir que un objeto puede ser definido en participio o en gerundio: es posible definir un elemento en términos acabados, es decir, en participio, cuando la historia, el devenir de lo estudiado no modifica lo estudiado. Un martillo, una mesa, un cuaderno, por ejemplo, son ideas cuya historia no precisamos conocer para comprender su significado. Al contrario, cuando la historia o devenir de aquello estudiado modifica el objeto estudiado, nos encontramos frente a una definición en gerundio. Apoyados en Sartre y la tradición existencialista, afirmamos que la persona humana es indefinible como participio, es decir, como algo acabado; 
suscribimos, en cambio, el dictum sartreano de que la persona humana es la única criatura en la que la existencia precede a la esencia ${ }^{8}$. La historicidad de lo humano, su ineluctable inserción en el flujo del tiempo, implican que todo intento por definir, de una vez por todas, lo humano - $\mathrm{O}$, peor, definir a un ser humano- pierda de vista que la excepcionalidad de lo humano, en general, y la unicidad individual, en lo particular, son incomprensibles cuando se busca imponerles definiciones ahistóricas. Esta historicidad del ser, que cuestiona la noción medieval de substantia —entendida como aquello que subyace inalterado - funciona, en la práctica, como una antidefinición, en tanto que, de entendérsele como definición, nos entrega apenas una tautología: un ser humano no es sino aquello que dicha persona mostró haber sido — su devenir mismo- al final de su vida.

La historia humana es rica en casos de conversión (metanoia) que marcan un antes y un después en la vida de una persona. La conversión de Saulo de Tarso en Pablo el apóstol de los gentiles, por ejemplo, supone una transformación absoluta: en línea con la tradición bíblica, la modificación de una letra de su nombre (recuérdese la transición Abram-Abraham, en Gen 17,5) atestigua un profundo cambio, un giro total en la persona. Así, "Saulo», un nombre que trae a la memoria la realeza israelita, es trocado por «Pablo», que significa "pequeño»". Este movimiento hace posible que Pablo, el converso, pueda afirmar que ha dejado de pertenecerse, se ha hecho pequeño para hacerse un instrumento de la causa que otrora persiguió: "ya no vivo yo, sino que Cristo vive en mí» (Gal 2,20). Comprender a Saulo-Pablo es imposible, evidentemente, sin un estudio cuidadoso de su historia.

Finalmente, es posible considerar el problema de la definición desde el punto de vista metafísico. En The Human Condition, Hannah Arendt ofrece una brillante formulación del problema metafísico que supone definir al ser humano:

«El problema de la naturaleza humana, la quaestio mihi factus sum de San Agustín ("he llegado a ser un problema para mí mismo"), no parece tener respuesta tanto en el sentido psicológico individual como

\footnotetext{
8 Jean Paul Sartre. Existentialism is a Humanism. New Haven: Yale University Press, 2007, 22.

9 Giorgio Agamben. The Time that Remains. Stanford: Stanford University Press, 2005, 9.
} 
en el filosófico general. Resulta muy improbable que nosotros, que podemos saber, determinar, definir las esencias naturales de todas las cosas que nos rodean, seamos capaces de hacer lo mismo con nosotros mismos, ya que eso supondría saltar de nuestra propia sombra... Dicho con otras palabras: si tenemos una naturaleza o esencia, sólo un dios puede conocerla y definirla, y el primer requisito sería que hablara sobre un "quién" como si fuera un "qué"»".

La distinción entre un "qué» y un «quién» no puede verificarse a través de la ciencia, por la razón de que el método científico reifica el objeto estudiado. Ahora bien, que la ciencia es incapaz de estudiar a un «quién» abre, lógicamente, la pregunta sobre el lugar de la ciencia en el edificio del conocimiento humano ${ }^{11}$. Esta pregunta es compartida por varios académicos e intelectuales contemporáneos ${ }^{12}$ que rechazan la idea de la ciencia como el último eslabón, el clímax de la racionalidad humana,

${ }^{10}$ Hanna Arendt. La Condición Humana. Barcelona: Paidós, 2016, 24. Max Horkheimer y Theodor Adorno apuntan en la misma dirección en su crítica a la razón ilustrada: «La Ilustración se relaciona con las cosas como el dictador con los hombres. Este los conoce en la medida en que puede manipularlos. El hombre de la ciencia conoce las cosas en la medida en que puede hacerlas. De tal modo, el en sí de las mismas se convierte en para él. En la transformación se revela la esencia de las cosas siempre como lo mismo: como materia o sustrato de dominio" (Theodor Adorno y Max Horkheimer. Dialéctica de la Ilustración. 8. a ed. Madrid: Trotta, 2006, 64-65).

${ }_{11} \mathrm{Al}$ respecto, Ratzinger dice: «Cuando la ciencia asevera que ella misma agota los límites del conocimiento humano, termina aterrizando en el terreno de lo no-científico» (Joseph Ratzinger. The Yes of Jesus Christ. Spiritual Exercises in Faith, Hope, and Love. New York: Crossroad, 2018, 11). La patología de la ciencia reside en su degeneración hybrística, esto es, el rechazo de sus propios límites. Ratzinger exige, por tanto, someter la razón técnica a los postulados morales: "La ratio technica debe incorporar una ratio ethica, a fin de que sólo podamos hablar de que algo funciona cuando hayamos asegurado un funcionamiento completamente responsable» (Joseph Ratzinger. "Technological security as a problem of social ethics". En Joseph Ratzinger in Communio, vol. 2, Anthropology and Culture, editado por David L. Schindler y Nicholas J. Healy, 48. Grand Rapids: William B. Eerdmans Publishing Company, 2013).

12 Ver Ruth Abbey. Charles Taylor. Teddington: Acumen, 2000, 63ff; Jason Blakely. Alasdair MacIntyre, Charles Taylor, and the Demise of Naturalism. Reunifying Political Theory and Social Science. Notre Dame: University of Notre Dame Press, 2016, 45-47; Hubert Dreyfus y Charles Taylor. Retrieving Realism, Cambridge: Harvard University Press, 2015; y Brad Gregory. The Unintended Reformation. How a Religious Revolution Secularized Society. Cambridge: The Belknap Press of Harvard University Press, 2012, 56-73. 
alegando que la condición de posibilidad misma de la ciencia exige un conocimiento precientífico ${ }^{13}$, y que los límites que la ciencia se impone a sí misma explican la necesidad de otras formas de acercarse a la realidad.

Arendt reflexiona sobre los límites de la ciencia, rechazando que en ella recaiga la tarea de dar respuesta a preguntas sobre la pertinencia de perseguir determinado programa científico. Por ejemplo, frente a la posibilidad de «crear» seres humanos a través de fecundación in vitro, clonación, etc., Arendt responde:

«La única cuestión que se plantea es si queremos o no emplear nuestros conocimientos científicos y técnicos en este sentido, y tal cuestión no puede decidirse por medios científicos; se trata de un problema político de primer orden y, por lo tanto, no cabe dejarlo a la decisión de los científicos o políticos profesionales» ${ }^{14}$.

13 Heidegger explica la necesidad de un conocimiento en tanto «mundo» como condición de posibilidad del conocimiento científico: «El Dasein no es jamás "inicialmente" un ente, por así decirlo, libre de estar-en, que de vez en cuando tiene ganas de establecer una "relación" con el mundo. Tal relacionarse con el mundo no es posible sino porque el Dasein, en tanto ser-en-el-mundo, es lo que es. Esta constitución del ser no se deriva primeramente del hecho de que fuera del ente con carácter de Dasein, haya también otros entes que están objetivamente presentes y que se encuentran con aquél. Estos otros entes pueden "encontrarse con" el Dasein sólo en la medida en que logran mostrarse ellos mismos dentro de un mundo" (Martin Heidegger. Being and Time. Albany: State University of New York Press, 2010, I-II §§57-58). La posibilidad de la ciencia, desde esta perspectiva, está dada por la experiencia del mundo en tanto mundo, como experiencia íntegra a la que somos lanzados. La ciencia, en tanto que esfuerzo de análisis y síntesis, esto es, en tanto disección de la experiencia-mundo, es posible solo a partir del reconocimiento de un estadio de conocimiento anterior y más general, es decir, ese estar en el mundo.

${ }_{14}$ Arendt, 15. El premio Nobel de Literatura, Imre Kértesz, sobreviviente del campo de concentración de Buchenwald, ilustra la a-moralidad científica que emerge en el campo de concentración: «Si se desea, pensé, es posible observar cómo muere de hambre una persona, al fin y al cabo, incluso puede tener interés científico» (Imre Kértesz. Sin Destino. Barcelona: Acantilado, 2006, 206). Ratzinger, por su parte, analiza tres casos donde la literatura aborda el problema de la pretensión humana de «crear al ser humano»: la historia del Golem en la Cábala judía; Fausto, de Goethe; y Brave New World, de Aldous Huxley. En los tres casos, la obra humana, el «homúnculo», termina saliéndose de las manos de su creador, causando estragos y dolor. Frente a estos ejemplos, Ratzinger reflexiona: "¿Se trata de una coincidencia que hasta ahora no exista una visión poética positiva de un futuro de la humanidad en la que la humanidad será producida in vitro? ¿ $\mathrm{O}$ existe más bien en dicha empresa una negación íntima y una eliminación ulterior de esa dimensión humana que la poesía trae a la luz?» (Joseph 
Cuando la ciencia se pretende capaz de ofrecer una definición de la naturaleza humana, viola los límites que ella misma se ha impuesto y termina ofreciendo nada más que consideraciones que atañen a un objeto que ha sido cosificado, con lo cual la persona desaparece y en su lugar emerge lo humano transformado en algo que puede ser medido, codificado, utilizado y, en el límite, descartado ${ }^{15}$.

El feto es, sin lugar a dudas, un caso límite en la discusión sobre el concepto de "persona humana». La dificultad que encuentra quien encara este problema es doble. En primer lugar, es necesario determinar si entre la fecundación del óvulo y el nacimiento existe una ruptura biológica, científicamente identificable, a través de la cual un organismo no personal adquiere el estatus de persona ${ }^{16}$. Las determinaciones legales

Ratzinger. "Man between reproduction and creation: Theological questions on the origin of human life". Joseph Ratzinger in Communio, vol. 2, Anthropology and Culture, 77. Grand Rapids: William B. Eerdman Publishing Company, 2013).

15 Cf. Francisco. Evangelii Gaudium. Ciudad del Vaticano, 2013, §53. El problema de la personalidad humana encuentra en la Shoah su más rotundo fracaso. El campo de concentración representa el lugar en el cual la vida humana es reducida a vida nuda por la fuerza desnuda de un estado de excepción que ha retirado el contenido de la ley, dejando a cargo la fuerza de la ley sin ley, esto es, la pura capacidad de coerción (Giorgio Agamben. Homo Sacer: Sovereign Power and Bare Life. Stanford: Stanford University Press, 1998, 20, 56; State of Exception. Chicago: The University of Chicago Press, 2005, 39; Remnants of Auschwitz. The Witness and the Archive. New York: Zone Books 1999, 69). La reducción de lo humano a lo no-humano es operada a través de la imposición de una definición puramente instrumental del otro que, aunada a prejuicios pseudocientíficos, es llevada al terreno de lo ontológico. Primo Levi describe esta reducción: el encuentro de miradas entre él y Pannwitz es horrífico por el hecho de que «no se trata de una mirada entre dos hombres». Levi escruta la mirada del Doktor: «El cerebro que gobernaba esos ojos azules y esas manos cuidadas decía: "Este algo en frente de mí pertenece a una especie que es obviamente oportuno suprimir. En este caso particular, uno debe primero asegurarse que no contiene algún elemento utilizable"» (Primo Levi. If this is a Man. New York: Orion Press, 1959, 123). Kértesz confiesa que llegó a internalizar ese pathos de distancia artificial descrito por Levi: "Veía bien sus caras, el color de sus ojos y de sus cabellos y otros rasgos personales, sus defectos, alguna que otra mancha en la piel; aquellos detalles tan humanos me hacían dudar: “¿Serían ellos parecidos a nosotros en el fondo, estarían hechos de la misma materia?”. Enseguida me di cuenta de lo equivocado que estaba, yo no era como ellos, claro que no» (Kértesz, Sin Destino, 126).

${ }_{16}$ Doctrinas que afirman la existencia de rupturas ontológicas en el feto pueden observarse asimismo en la historia del cristianismo. Tomás de Aquino sostiene que «el alma intelectual es creada por Dios al final de la generación humana», lo que 
que permiten el aborto antes de determinado número de semanas de gestación parecen seguir esta estrategia, comúnmente justificada a través de argumentos funcionalistas: el umbral solía fijarse en el momento en que existe ritmo cardiaco o, en tiempos recientes, cuando se ha desarrollado el sistema nervioso central, que atestiguaría la capacidad de sentir dolor.

Contra estas definiciones podemos preguntar: ¿qué determina que una u otra función biológica determine la existencia e inexistencia de una persona humana? Insistamos: si la persona es un "quién», ¿cómo es posible explicar su personalidad observándola como un «qué»? Estas definiciones son cerradas y formuladas en participio, con lo cual se viola el carácter histórico y la unicidad de la persona.

Una segunda dificultad se refiere no ya a la evolución promedio del feto y sus características fisiológicas, sino al significando, necesariamente cifrado en lenguaje metafísico, que estos hallazgos tienen para la pregunta sobre el estatus ontológico del feto. La definición de persona de Raymond Bergner es asintótica, puesto que, en su opinión:

«[...] tradicionalmente extendemos este concepto a ciertas transformaciones del caso paradigmático en el que los individuos, por ejemplo, (a) sólo adquirirán la habilidad para comportarse deliberadamente en un tiempo posterior (por ejemplo, menores); (b) han sufrido daño

implica, de acuerdo con David Albert Jones, que el alma se deposita «luego de que el cuerpo del embrión se ha formado, lo que para los niños se pensaba ocurría alrededor de los 40 días» (David A. Jones. "Aquinas as an Advocate of Abortion? The Appeal to 'Delayed Animation' in Contemporary Christian Ethical Debates on the Human Embryo”. Studies in Christian Ethics 26-1 (2013): 101. Jones se refiere a la Suma Teológica de Aquino: I, q.118, a. 2, ad 2). Igualmente, en la Summa Contra Gentiles (II. Cap. 89), Aquino afirma: «Porque, como el alma se une al cuerpo como forma, no se une sino al cuerpo del cual es acto. Pues el alma es "el acto del cuerpo organizado". Luego, antes de estar organizado el cuerpo, el alma no está en el semen actualmente, sino sólo en potencia o virtualmente». El progreso científico generó fuertes presiones sobre la Iglesia para que esta abandonara la doctrina de la «animación tardía». Tal como explica Jones, «el aparente cambio de opinión de la Iglesia ocurrió no porque esta abandonó sus principios éticos y filosóficos, sino porque estos mismos principios estaban ahora informados por una nueva biología» (Jones. "Aquinas as an Advocate", 106). La teología misma ha abandonado, asimismo, una visión objetivista del alma. Por ejemplo, Ratzinger asevera que «el alma no es una entidad oculta que la persona tiene, sino el dinamismo de una apertura ilimitada, que al mismo tiempo implica participación en lo infinito, en lo eterno» (Joseph Ratzinger. "Beyond Death". Joseph Ratzinger in Communio, vol. 2, Anthropology and Culture, 12. Grand Rapids: William B. Eerdmans Publishing Company, 2013). 
a su habilidad debido a desgracias como el autismo, el daño cerebral o la demencia; o (c) se encuentran en coma o estados vegetativos ${ }^{17}$.

La definición, sin embargo, no resuelve definitivamente el estatus ontológico del feto: mientras que, como se discutirá en la siguiente sección, la gestación humana es un proceso ininterrumpido en el cual no existe ruptura observable alguna que pueda calificarse, fuera de toda duda, como indicativa de un cambio en el estatus ontológico del organismo, esto no descarta la posibilidad, qua posibilidad, de que, por ejemplo, un conjunto de blastómeros sea no más que una persona en potencia. Se evidencia aquí el problema metafísico, es decir, la imposibilidad de resolver definitivamente la cuestión de la personalidad del feto.

El feto es, empero, un caso limítrofe no solo en sentido metafísico. Cuando hablamos del carácter histórico de la persona, comúnmente no nos referimos a la vida intrauterina: la edad de la persona, por ejemplo, comienza a contar a partir del nacimiento. Ahora bien, la ciencia misma nos muestra la impresionante variabilidad de condiciones en las que los seres humanos pueden nacer: Lyla Stensrud, por citar un ejemplo, nació en Texas prácticamente a medio camino de gestación: a las 21 semanas, 4 días de gestación, pesando apenas 14.4 onzas (408 gramos) y midiendo 10 pulgadas $(25.4 \text { centímetros })^{18}$. No hay duda, pues, de que la historia extrauterina de muchos seres humanos puede dar inicio prematuramente: ¿implica esta posibilidad que existe al menos cierto nivel de arbitrariedad entre la distinción entre vida intra y extrauterina? Y, si este es el caso, ¿no resultaría sensato extender el análisis de la persona en gerundio a la vida del feto?

Lejos de nuestra intención, por supuesto, está definir el momento en que puede hablarse de "persona humana» en el proceso de gestación humano. Al contrario, nuestro objetivo ha sido mostrar algunos de los problemas y arbitrariedades que se cometen en la búsqueda de definiciones operacionales.

Quizá sea posible, finalmente, mostrar estos problemas más claramente si salimos del caso del feto y nos enfocamos en el otro momento de la vida humana que, desde tiempos inmemorables, ha despertado la

\footnotetext{
17 Bergner. "What is a Person?", 77.

18 A. Pawlowski. "Miracle baby': Born at 21 weeks, she may be the most premature surviving infant”. Today. Noviembre 9, 2017. Disponible en: https://www.today. com/health/born-21-weeks-she-may-be-most-premature-surviving-baby-t118610
} 
imaginación metafísica. Giorgio Agamben encuentra que las mismas dificultades que hemos identificado para el caso del aborto han emergido cuando se ha buscado definir la muerte. También en este caso encontramos un juego similar entre ciencia, metafísica y política. Mientras que el criterio para considerar muerta a una persona humana fue, durante mucho tiempo, la cesación de la respiración y del pulso cardiaco, la posibilidad de donar órganos de pacientes con muerte encefálica a fin de realizar trasplantes que salven vidas de terceros, introdujo nuevas dificultades en el debate ${ }^{19}$. Así, «[u]na vez que las pruebas médicas han confirmado la muerte completa del cerebro (no sólo del neurocortex sino también del tronco cerebral), el paciente debía considerarse muerto, incluso si, gracias a la tecnología capaz de mantener la vida, continuaba respirando ${ }^{20}$. Agamben continúa su estudio, demostrando que la distinción vida/muerte ha caído en una zona de indefinición tal que la única solución viable ha sido rendirse al poder biopolítico del Estado como último ente capaz de dirimir la cuestión — tal como observamos en la primera nota al pie de este trabajo-:

19 En la entrada sobre del Dictionary of Public Health encontramos la siguiente definición de «muerte»: "Cesación de la actividad cardiovascular, respiratoria y neurológica por un periodo suficiente de tiempo que causa un deterioro patológico irreversible en los órganos vitales. La definición tradicional de muerte - la cesación irreversible de las funciones circulatorias, respiratorias y neurológicas- se ha vuelto menos válida desde el desarrollo de sistemas de soporte vital y dispositivos para ventilar los pulmones y para simular artificialmente las contracciones del músculo del corazón. Los órganos individuales y los sistemas del cuerpo pueden "morir", pero la vida cesa sólo cuando una persona experimenta muerte encefálica, luego de la cual los órganos pueden ser recolectados» (John Last. "Death". In Dictionary of Public Health. New York: Oxford University Press, 2007). Compárese esta peculiar forma de definir una «muerte» con la reflexión sobre la muerte de Agustín de Hipona, mil quinientos años atrás: «Decimos, entonces, que existen tres tiempos separados —antes de la muerte, en la muerte, y después de la muerte-que corresponden a tres estados: viviendo, muriendo, y muerto. Y es muy difícil definir cuando un hombre está muerto o muriendo: esto es, en un estado en el que no está vivo, que ocurre antes de la muerte, ni muerto, lo que ocurre después de la muerte, sino muriendo, lo que ocurre en la muerte» (Agustín. The City of God Against the Pagans. Cambridge: Cambridge University Press, 2014, XIII.11: 552, énfasis nuestro). Resulta sorprendente observar que ambas estrategias parecen arribar a una conclusión similar, esto es, la muerte como un momento de indistinción existencial, incluso cuando cada una parte de premisas completamente distintas.

20 Agamben. Homo sacer, 162 (trad. Valencia: Pre-Textos, 2006, 209). 
«Hoy, la vida y la muerte no son conceptos científicos propiamente sino más bien conceptos políticos, que como tales adquieren un significado político precisamente sólo a través de la decisión... El cuarto de hospital donde el neomort, la persona en coma, y el faux vivant se balancean entre la vida y la muerte delimita un espacio de excepción en el que la vida nuda como tal, enteramente controlada por el hombre y su tecnología, aparece por primera vez. Y en tanto se trata, precisamente, de una cuestión no ya de vida natural sino de la encarnación extrema del homo sacer (la persona comatosa ha sido definida como un ser intermedio entre el hombre y el animal), lo que está en juego es, una vez más, la definición de una vida que puede ser asesinada sin la comisión de un homicidio (y que es, como el homo sacer, "insacrificable” en el sentido de que obviamente no puede ser asesinada luego de recibir una condena de muerte) ${ }^{21}$.

La reducción del agonizante a homo sacer es simétrica a la posibilidad de reducir al feto a la condición de vida no-humana, que por ende puede matarse sin cometer un homicidio. Las dificultades, asimismo, para definir con precisión las ideas de «vida» $\mathrm{y}$ «muerte» exponen nítidamente la condición humana no ya como vida biológica que puede fácilmente ser puesta bajo el microscopio del científico, sino como paradoja y misterio que tercamente resiste y termina escapando al control humano.

A partir de las tres estrategias de definición analizadas podemos decir, de manera sintética, que todo estudio que pretenda aportar elementos para una definición del estatus ontológico del feto: (a) debe privilegiar definiciones asintóticas, puesto que el feto representa un caso limítrofe en el conjunto de manifestaciones de la personalidad humana; $(b)$ debe utilizar definiciones en gerundio, pues ellas respetan la dimensión histórica y unicidad de los seres humanos ${ }^{22}$; y (c) debe reconocer que toda

${ }^{21}$ Ibid., 164-165.

${ }^{22}$ Charles Taylor captura este rasgo antropológico, es decir, la unicidad e irrepetibilidad de cada ser humano, a través de su ética de la autenticidad y política del reconocimiento (Charles Taylor. The Ethics of Authenticity. Cambridge: Harvard University Press, 2003 y “The Politics of Recognition”. En Multiculturalism, editado por Amy Gutmann. Princeton: Princeton University Press, 1994, 25-74, respectivamente). La autenticidad, entendida como un valor moral generado por la modernidad, demanda el reconocimiento como contraparte política. La dialéctica autenticidadreconocimiento muestra, asimismo, el carácter dialógico-comunitario de la persona humana: solo cuando el otro me reconoce, aquello que soy más íntimamente sale a la superficie en plenitud. 
definición en sentido estricto, esto es, una que busque ir más allá de una definición útil para proporcionar, en cambio, una definición esencialista del estatus ontológico del feto, incluirá necesariamente elementos metafísicos, toda vez que la misma pretende definir un «quién» antes que un «qué».

$\mathrm{Si}$, por ende, toda definición de la «persona» solo puede ser asintótica, formulada en gerundio, y contar con elementos metafísicos, ¿es posible decir todavía algo interesante sobre el estatus ontológico del feto? En las siguientes secciones proponemos que las limitaciones epistemológicas discutidas nos obligan a adoptar una postura prudencial, esto es, el reconocimiento de la insolubilidad definitiva del misterio humano. Esta conclusión se apoya tanto en los datos aportados por la ciencia —que demuestran que la gestación es un proceso continuo compartido por el feto y la madre como organismos claramente diferenciados- así como por la definición de la persona humana entendida desde una metafísica particular, a saber, desde la teología cristiana.

\section{LOS DATOS DE LA CIENCIA}

La ciencia, entendida como «una forma de examinar, explicar, reflexionar y predecir fenómenos naturales a través de la observación sistemática, la experimentación y la inferencia lógica, a fin de formular y probar hipótesis con el objeto de establecer, aumentar y confirmar conocimiento ${ }^{23}$ es una herramienta a través de la cual es posible establecer relaciones entre fenómenos. Gracias al avance de la ciencia y la tecnología, en la actualidad podemos describir con precisión los acontecimientos biológicos del desarrollo del ser humano dentro del vientre materno.

En el siglo XVII, Anton van Leeuwenhoek inventó el microscopio, inaugurando la descripción de un mundo antes desconocido: la microbiología. A él se le atribuye la descripción y visualización de los espermatozoides en $1677^{24}$. Algunos años antes, Regnier de Graaf ya había descrito el desarrollo folicular en el ovario femenino. Casi dos siglos después, en 1827,

23 Last. "Science".

${ }^{24}$ Howard Gest. "The discovery of microorganisms by Robert Hooke and Antoni van Leeuwenhoek, fellows of the royal Society". Notes and Records of the Royal Society of London, 58-2 (2004). 
Karl Ernst von Baer descubre la existencia del ovocito, célula clave en la génesis y perpetuación de la especie humana.

Gracias a la genética, la biología molecular y la embriología, hoy sabemos que tanto el espermatozoide como el ovocito culminan su proceso meiótico ${ }^{25}$ únicamente cuando ocurre la fecundación —es decir, la unión entre gametos haploides-y se lleva a cabo la fusión o acoplamiento del material genético de ambas células, conformando así una célula diploide - es decir, aquella que posee dos sets de cromosomas- totalmente diferente de sus predecesoras, que se denomina cigoto.

El cigoto se diferencia claramente del resto de células del cuerpo de la madre a partir de su contenido genético ya que, a diferencia del resto de los ovocitos de la madre, este contiene genes de origen tanto materno como paterno. El cigoto es la única célula totipotencial, es decir, que posee la capacidad de dividirse generando células cuya diferenciación o especialización gradual dará origen a los diferentes órganos y tejidos del embrión y sus anexos, que le permitirán su desarrollo morfológico y la interrelación con el cuerpo materno del que sin duda depende para poder existir ${ }^{26}$.

La duración del cigoto como célula única es solo de veinticuatro horas; a partir de ahí se generan dos células diploides (blastómeros) con la misma información genética y la capacidad totipotencial antes referida, que continuarán dividiéndose mediante procesos mitóticos propios cada

${ }^{25}$ Se entiende por meiosis la «división celular exclusiva de las gónadas en las que las parejas de cromosomas en las células germinales precursoras se segregan en dos células hijas (es decir, haploides), en un complejo proceso que conlleva a la formación de gametos masculinos y femeninos que transmitirán las características hereditarias a la siguiente generación luego de la fertilización». (Last. "Meiosis").

${ }^{26}$ Camosy analiza, en este respecto, la sugerencia de Robin Alta Charo, en el sentido de que «con el advenimiento de la clonación de mamíferos, cada célula individual es ahora una persona potencial — aunque quizá la probabilidad de que una célula particular se convierta en una persona a través de transferencia nuclear es extremadamente pequeña». Camosy opone el argumento que Massimo Reichlin hace apoyado en la diferencia aristotélica entre potencia activa y pasiva: «Un árbol, en su potencia pasiva, es una posible mesa... Sin embargo, esto no significa de ninguna forma que el árbol sea ya una mesa. Es necesario un "evento capaz de cambiar la naturaleza" del árbol para realizar este potencial. Las potencias activas, por el contrario, "son aquellas inherentes a la naturaleza misma del ser, cuyo principio de actualización es la naturaleza misma del ser"» (Camosy. "Common Ground", 587). Desde esta perspectiva, solo el cigoto puede ser considerado una persona en potencia activa. 
doce o quince horas. Cuarenta y ocho horas después de la fecundación, el conjunto de ocho blastómeros inicia una fase de compactación producida por la fusión y unión entre los mismos. Al conjunto de blastómeros se le denominará mórula. La totipotencialidad se mantiene hasta que el embrión cuenta con 8 células. A partir del día cuatro da inicio la diferenciación celular.

Cinco días después de la formación del cigoto encontramos aproximadamente 250 células (blastocistos), en las cuales ya se observa la división entre blastómeros, que conforman al embrioblasto, y las blastómeras, que conforman el trofoblasto, que dará origen a la placenta y demás tejidos extraembrionarios. Entre los días seis y nueve postfecundación se inicia la implantación, con lo que comienza una etapa de convivencia e interacción entre el cuerpo de la madre y el embrión. Dicha interacción está mediada y autorregulada por diferentes mecanismos y cambios bioquímicos, originados por ambas partes, que tienen como objetivo el desarrollo de vasos sanguíneos y tejido que permita el intercambio de nutrientes y de gases sanguíneos que garanticen la subsistencia y mantenimiento del feto.

De lo dicho hasta este momento se infiere que en el corto tiempo de una semana la existencia de un embrión diferenciado es indiscutible, que continuará su desarrollo morfológico con independencia de las demás células y órganos de la madre.

Durante la segunda semana, las células del embrioblasto se dividen en dos capas -epiblasto e hipoblasto- que originarán tres capas embrionarias —endodermo, mesodermo y ectodermo - durante la tercera semana, y de las cuales se derivarán, a su vez, todas las células, tejidos y órganos. Al final de la segunda semana, el ectodermo inicia la diferenciación del neuroectodermo, dando paso a la formación del sistema nervioso central y periférico, que no adquiere su desarrollo máximo sino hasta los tres años de edad postnatal. Este hecho sugiere no solo la inexistencia de rupturas o disrupciones ontológicas en el feto sino, quizá más importante aún, el hecho de que el desarrollo humano no termina en el parto, el cual si bien inaugura una nueva etapa caracterizada por la rápida adquisición de autonomía del bebé vis-à-vis de la madre, tampoco puede ser considerado, en sí mismo, como una ruptura ontológica de magnitud suficiente como para establecer diferencias entre el antes y el después de dicho ser.

En la tercera semana ocurre la neurulación - es decir, el proceso por el que, a partir del ectodermo, se forma la placa neural de la que se originan el tubo neural y la cresta neural, que dan origen al sistema nervioso- $\mathrm{y}$ 
la gastrulación, responsable de la formación de las tres hojas germinativas: ectodermo, mesodermo y endodermo.

De la cuarta a la octava semana se produce la organogénesis, que constituye el periodo de mayor desarrollo de los distintos órganos y sistemas del cuerpo, siguiendo un orden céfalocaudal. Hacia el día 22 postfecundación se forma el primordio cardiaco e inicia el latido cardiaco autónomo, a pesar de tener una longitud de tan solo tres milímetros. Hacia el día 26 se inicia el desarrollo del ojo, los oídos, la boca, el sistema urinario, el sistema gastrointestinal y los cuerpos vertebrales. En el día 28 inicia el desarrollo de las fosas nasales, así como las extremidades superiores e inferiores, que miden apenas cinco milímetros de longitud. Entre la quinta y sexta semanas se delinean los dedos de las extremidades, el codo, rodilla, párpados, pabellón auricular y el hígado. El embrión llega a medir 16 milímetros de longitud cráneocaudal. Entre la séptima y octava semanas se produce el delineamiento de la nariz, mandíbula y labios. El embrión llega a medir 29 milímetros.

El periodo comprendido entre la semana nueve y la cuarenta se conoce como periodo fetal, en el cual se produce la maduración y diferenciación de los diferentes órganos y tejidos, al tiempo que continúa el crecimiento de todo el cuerpo, iniciando con un peso promedio de 10 a 15 gramos y una longitud céfalocaudal de 5 a 6 centímetros, y alcanzando, en la trigésima octava semana, un peso promedio de 3 kilogramos y una longitud céfalocaudal de 36 centímetros.

Ahora bien, respecto a la pregunta, surgida en la sección anterior, de si el feto es capaz o no de sentir dolor, la evidencia generada por la ciencia parece inclinarse hacia la afirmativa. Si bien Carlo Bellieni reconoce que «es muy difícil determinar si un sujeto que no puede expresar sus propios sentimientos está sintiendo, en efecto, dolor», los datos que arroja su estudio del desarrollo de la red de nociceptores, es decir, los nervios que conducen las sensaciones de dolor al cerebro ${ }^{27}$ muestran que

«[1]os nociceptores se encuentran extensamente presentes en la piel del feto, al menos en la misma densidad que en los adultos. Los axones de los mismos alcanzan la piel entre las semanas 11 y 15 de gestación, y la mucosa en la semana $20 .$. La mayoría de los nervios serán precozmente mielinizados, comenzando entre la semana 12 y 14 de

${ }_{27}$ P. H. Collin. "Nociceptor". En Dictionary of Medicine. New York: Routledge, 2014. 
gestación, garantizando una más alta velocidad de conducción de los impulsos que llevan al cerebro. Incluso los neuromediadores de dolor, como la sustancia $\mathrm{P}$ y las encefalinas aparecen tempranamente, entre las semanas 8-10 y 12-14, respectivamente, de gestación. La producción de opioides endógenos comienza en el cerebro alrededor de la mitad del embarazo... Otra estructura importante está también presente en la vida fetal: la amígdala. La amígdala es el centro del miedo y de ansiedad en los animales, y su aparición temprana podría ser una señal de que incluso estas sensaciones, aunque rudimentarias, pueden ser sentidas dentro del útero» ${ }^{28}$.

A partir de los datos que la ciencia arroja respecto del desarrollo biológico del embrión y el feto, es posible concluir que el desarrollo y crecimiento del ser humano es un proceso continuo en el tiempo. Si bien intervienen en dicho proceso cambios de tipo cuantitativo y cualitativo de la mayor importancia, en todo momento se verifica una evolución ininterrumpida que corre desde la formación del cigoto hasta la vejez, proceso en el cual se observa un importante y vasto repertorio de divisiones celulares denominadas mitosis, así como de diferenciación y muerte celular que, visto desde un punto de vista macroscópico, hacen referencia a la totalidad del cuerpo humano, que va sufriendo los cambios propios de su temporalidad con un inicio y un fin.

\section{LA «PERSONA» DESDE LA TEOLOGÍA}

La teología cristiana deriva la idea de persona humana de las nociones a través de las cuales la patrística buscó entender el misterio trinitario. En los albores del cristianismo, los padres de la Iglesia buscaron una fórmula que describiera la novedad cristiana respecto del monoteísmo judío, al tiempo que la distinguía del paganismo politeísta.

Tertuliano ofreció dicha fórmula. Dios, afirmó, es una substantia tres personae. El cristianismo adoptó la noción griega de «persona» (prósopon), que refería a las máscaras que los actores usaban para dar vida a representaciones dramáticas. La idea de persona fue entendida, por ende, en términos de relación, que Joseph Ratzinger describe como «la

${ }^{28}$ Carlo V. Bellieni. "New Insights into Fetal Pain". Seminars in Fetal and Neofetal Medicine 24 (2019): 1. 
tercera categoría fundamental, situada entre sustancia y accidente, las dos grandes formas categóricas del pensamiento antiguo ${ }^{29}$. Así pues, cuando leemos en el libro del Génesis que el hombre fue creado «a imagen y semejanza» divina, debemos entender que la persona humana refleja la economía divina.

Ratzinger describe esta economía divina en términos de las relaciones ser-para (Padre), ser-desde (Hijo) y ser-con (Espíritu Santo), que corresponden respectivamente a los principios de responsabilidad, dependencia y solidaridad. La persona humana es, pues, aquella criatura cuya íntima configuración está gobernada por las relaciones "para», «desde» y «con», esto es, las relaciones gobernadas por la responsabilidad, que presupone la libertad; la dependencia, que describe la radical incompletitud del «yo»; y la solidaridad, la misma que se desprende de la natural sociabilidad humana ${ }^{30}$.

Markus Mühling y David Gilland ofrecen una definición de la persona partiendo de una lógica análoga. Para ellos, la persona humana es, también, un «ser-desde-y-para-otros». Este ser «desde» y «para» otros implica, en su opinión, que "una persona individual es inconcebible», puesto que «ser persona siempre significa encontrarse en relaciones constitutivas para uno mismo y los otros $»^{31}$. El ser mismo de la persona es, por ende, una construcción dialógica, no monológica: la hechura de una historia personal no se conjuga en singular, sino en plural ${ }^{32}$. Ratzinger identifica esta inexorable co-constitución en el caso del aborto, donde «el ser de otra persona se encuentra tan íntimamente entretejido con el ser de esta persona, la madre, que en el momento presente puede sobrevivir sólo estando físicamente con la madre. Esta unidad, sin embargo, no elimina la otredad de este ser o nos autoriza a disputar su distinta mismidad ${ }^{33}$. La

29 Joseph Ratzinger. "Concerning the notion of the Person in Theology". Joseph Ratzinger in Communio, vol. 2, Anthropology and Culture, 104. Grand Rapids: William B. Eerdmans Publishing Company, 2013.

30 Joseph Ratzinger. "Truth and Freedom". Joseph Ratzinger in Communio, vol. 2, Anthropology and Culture, 159. Grand Rapids: William B. Eerdmans Publishing Company, 2013.

${ }^{31}$ Markus Mühling, y David Gilland. "Which Relationality? Whose Personhood? The Christian Understanding of the Person, 'After-Birth Abortion' and Embryonic Stem Cell Research". Studies in Christian Ethics 26-4 (2013): 476.

32 Charles Taylor. The Language Animal. Cambridge: Harvard University Press, 2016, 55.

33 Ratzinger. “Truth and Freedom”, 158. 
relación entre el feto y la madre, como hemos explicado, aproxima una situación de dependencia y responsabilidad absolutas, sin que por ello se siga que los intereses de la madre - así como el multicitado argumento de la absoluta autonomía de la mujer sobre su cuerpo durante el embara$z o$, que ignora tanto que el feto, qua organismo, es independiente de ella, como que las estructuras antropológicas de responsabilidad y dependencia median la existencia humana- deben prevalecer sobre los del feto.

Mühling y Gilland afirman, asimismo, que las personas no son estáticas, sino que «pertenecen irreduciblemente dentro de narrativas históricas que ellas mismas poseen». Estas historias no son vividas en aislamiento sino, al contrario, son ellas mismas un tejido interpersonal, con lo cual la dimensión a o prepersonal «debe ser asimismo entendida como necesariamente constitutiva de la personalidad creativa ${ }^{34}$. Contra la noción individualista que ve en el sujeto nada más que una criatura capaz de legislar para sí misma, la idea de persona humana problematiza al individuo-mónada, mostrando que gran parte de su hechura está cosida con hilos prestados.

La persona, finalmente, "está siempre en proceso, en devenir» y esta personalidad solo puede entenderse en términos de perfectibilidad. La dimensión histórica de la persona emerge aquí con toda claridad. Sartre está en lo correcto: la persona humana se revela como criatura histórica y, por ende, como el ser que parece evadir todo intento de definición.

Cuando revisamos las intuiciones que el magisterio católico ofrece, encontramos que el catolicismo reconoce que la pregunta por el estatus ontológico del feto representa un caso limítrofe que fuerza definiciones asintóticas. Así, por ejemplo, en 1974 la Congregación para la Doctrina de la Fe afirmó que, desde el punto de vista moral, «aunque hubiese duda sobre la cuestión de si el fruto de la concepción es ya una persona humana, es objetivamente un pecado grave el atreverse a afrontar el riesgo de un homicidio» ${ }^{35}$. En la instrucción Donum Vitae (1987), por su parte, dicha Congregación estableció que «[e]l ser humano debe ser respetado y tratado como persona desde el instante de su concepción ${ }^{36}$. Finalmen-

\footnotetext{
34 Mühling y Gilland. "Which Relationality?”, 476.

35 Congregación para la Doctrina de la Fe. Declaración sobre el Aborto. Ciudad del Vaticano: Libreria Editrice Vaticana, 1974, §13, énfasis nuestro.

${ }^{36}$ Congregación para la Doctrina de la Fe. Instrucción Donum Vitae. Sobre el Respeto de la Vida Humana Naciente y la Dignidad de la Procreación. Ciudad del Vaticano: Libreria Editrice Vaticana, 1987, §I.1, énfasis nuestro; cf. Catecismo de la Iglesia Católica, §2274.
} 
te, en su encíclica Evangelium Vitae (1995), Juan Pablo II reconoció que «la presencia de un alma espiritual no puede deducirse de la observación de ningún dato experimental» y, por ende, que «más allá de los debates científicos y de las mismas afirmaciones filosóficas en las que el Magisterio no se ha comprometido expresamente, la Iglesia siempre ha enseñado, y sigue enseñando, que al fruto de la generación humana, desde el primer momento de su existencia, se ha de garantizar el respeto incondicional que moralmente se le debe al ser humano en su totalidad y unidad corporal y espiritual» ${ }^{37}$.

Resulta evidente que el catolicismo no busca resolver la cuestión de la personalidad del feto. Contundentemente, por el contrario, afirma la Iglesia que «no es incumbencia de las ciencias biológicas dar un juicio decisivo acerca de cuestiones propiamente filosóficas y morales, como son la del momento en que se constituye la persona humana y la legitimidad del aborto» ${ }^{38}$. Por el contrario, «el misterio del hombre sólo se esclarece en el misterio del Verbo encarnado ${ }^{39}$, porque «[s]ólo la fe permite penetrar en el misterio» ${ }^{40}$.

Que la ciencia no pueda penetrar el misterio de la persona no es óbice, por supuesto, para considerar los datos de la ciencia, los cuales, como se ha expuesto, ofrecen valiosa evidencia de que, en la gestación, encontramos dos organismos perfectamente delimitados, que, no obstante, comparten un proceso ininterrumpido que constituye un caso paradigmático de las categorías de dependencia y responsabilidad como elementos antropológicos fundamentales.

Asimismo, la postura de la Iglesia es manifiestamente prudencial: incluso si los datos de la ciencia, o el sentido común, o el depósito de la revelación, sugieren la personalidad del feto, la Iglesia no adopta una definición cerrada, sino que reconoce las dificultades que el tema ha tenido históricamente ${ }^{41}$.

37 Juan Pablo II. Evangelium Vitae. Ciudad del Vaticano: Libreria Editrice Vaticana, 1995, §60.

${ }_{38}$ Congregación para la Doctrina de la Fe, Declaración sobre el Aborto, §13.

39 Concilio Vaticano II. Gaudium et Spes. Ciudad del Vaticano: Libreria Editrice Vaticana, 1965, §22.

40 Juan Pablo II. Fides et Ratio. Ciudad del Vaticano: Libreria Editrice Vaticana, $1998, \S 13$.

${ }^{41}$ Congregación para la Doctrina de la Fe, Declaración sobre el Aborto, §7. 
La postura de la Iglesia adopta la forma del como si, que implica una toma de postura prudencial respecto a preguntas que caen en terreno metafísico. En sus Pensées, Pascal recurre a la estructura "como si» (comme si) en repetidas ocasiones. Debemos enfrentar la pasión, por ejemplo, actuando "como si tuviésemos sólo ocho horas de vida» ${ }^{42}$. Más interesante resulta su crítica a la sociedad: «Somos ingenuos al depender de la sociedad de nuestros semejantes. Desgraciados como somos, ellos no nos ayudarán; más bien moriremos solos». Pascal aconseja: «Il faut donc faire comme si on était seul»: Debemos actuar como si estuviésemos solos ${ }^{43}$.

¿Qué implica esta introducción del «como si» frente a cuestiones metafísicas? En su estudio sobre Hans Vaihinger, Kwame Appiah entiende el «como si» (als $o b$ ) en términos de la utilidad que la consideración de argumentos falsos pudiese tener para la comprensión de la realidad:

«La idea central es que Vaihinger está interesado en el rol de la falsedad [untruth] en la reflexión sobre la realidad, no en la utilidad de decir falsedades... Vaihinger está interesado, por ende, en casos en los que el usuario de la ficción está consciente, o puede volverse consciente, de que lo que está pensando no es verdadero» ${ }^{44}$.

¿Se trata, en el caso del «como si» de la Iglesia católica, de la utilización de un argumento cuya falsedad es consciente? En nuestra opinión, el als ob descrito por Appiah no toma suficientemente en serio las tensiones racionales en el individuo, por lo que termina decantándose por la reducción de las teorías a meras ficciones o mitos que, no obstante, pueden ser útiles. Nuestro argumento, empero, no es utilitarista, sino epistemológico y metafísico.

Debemos, pues, entender la estructura «como si» de una forma completamente distinta. Ratzinger sigue a Pascal en lo que toca al problema de un conocimiento último y claro de Dios:

«Nadie puede poner a Dios y su reino sobre la mesa frente a otro hombre, y el creyente, por supuesto, tampoco. Sin importar cuán fuertemente la incredulidad se sienta justificada, no puede olvidar el misterioso sentimiento inducido por las palabras "Y sin embargo,

${ }^{42}$ Blaise Pascal. Pensées and Other Writings. New York: Oxford University Press, 2008, §203.

43 Ibid., 211.

${ }^{44}$ Kwame A. Appiah. As If. Idealization and Ideas. Cambridge: Harvard University Press, 2017, 4. 
quizá es verdad". Ese "quizá" es la tentación ineludible a la que nadie puede sustraerse... Digámoslo de otro modo: tanto el creyente como el no creyente participan, cada uno a su modo, en la duda $y$ en la fe, siempre y cuando no se oculten a sí mismos y a la verdad de su ser ${ }^{45}$.

Que la existencia de Dios no puede describirse sino como tensión entre duda y fe se entiende, Ratzinger continúa, porque «Dios no es sólo aquel que actualmente está fuera de mi campo de visión pero que podría ser visto si fuera posible ir más lejos; no, Dios es el ser que está esencialmente fuera de mi campo de visión, sin importar cuánto se extienda este» ${ }^{46}$. Ratzinger está en línea no solo con Pascal, quien instruye: «S’il y a un Dieu, il est infiniment incompréhensible», si hay un Dios, entonces es infinitamente incomprensible ${ }^{47}$, sino con Agustín, quien afirma: «Si enim comprehendis, non est Deus», si lo comprendes, entonces no es Dios.

La fe, para Ratzinger, no implica reconocer una falsedad por la utilidad que esta reporta. La fe implica, al contrario, un posicionamiento

45 Joseph Ratzinger. Introduction to Christianity. San Francisco: Ignatius Press, 2004, 46.

${ }^{46}$ Ratzinger, 2004, 50; cf. Jn 1: 18. Brad S. Gregory describe el movimiento desde la concepción cristiana de la otredad absoluta de Dios vis-à-vis el ser humano hacia la cosificación de Dios en el pensamiento nominalista: «De acuerdo con Aquino, Dios era, en términos metafísicos, incomprehensible, esse - no un ser [being] sino el acto de ser mismo [to-be], en el que todas las criaturas participaban en tanto que existían y a través del cual la creación misma era misteriosamente sostenida. En el nominalismo occamista, en cambio, en tanto que Dios existía, "Dios" tenía que denotar alguna cosa, una entidad real discreta, un ens — sin importar cuán distinta dicha entidad fuera de todo lo demás» (Brad S. Gregory. The Unintended Reformation. How a Religious Revolution Secularized Society. Cambridge: The Belknap Press of Harvard University Press, 2012, 38). De acuerdo con Gregory, el principio de univocidad —la idea, defendida por John Duns Scotus, de que Dios tenía que compartir con las demás criaturas, cuando menos, el hecho de participar del «ser»— unido a la navaja de Occam, está en el origen del desencantamiento del mundo descrito por Weber, así como de la errónea pretensión del ateísmo de poder "probar» la inexistencia de Dios a través de la ciencia: «El punto nodal no es, como comúnmente se cree, que la investigación empírica del mundo natural hizo o hace la existencia de un Dios trascendental cada vez más implausible. Es más bien que esta presuposición históricamente depende, y continúa dependiendo, de una concepción de Dios como un agente supernatural hipotético que compite con la causalidad natural, polémicamente vulgarizada, por ejemplo, en los despotriques de Richard Dawkins acerca de la "hipótesis sobre Dios" así como su "espejismo de Dios"» (Ibid., 55-56).

47 Pascal, Pensées, §233. 
existencial, una respuesta de carácter general al problema de la existencia. Frente a la pregunta por el sentido de la existencia, el creyente se decanta por una posición existencial que afirma que la realidad no se agota en lo fenoménico; el no creyente, por su parte, asevera que no hay vida después, ni detrás, de esta vida. La fe o la incredulidad implican respuestas existenciales de primer orden, pues a través de ellas se estructura la vida misma del individuo ${ }^{48}$.

De la misma forma que en el caso del aborto, la pregunta por la existencia de Dios aterriza en el terreno moral, por lo tanto, en la forma del «como si»:

«La búsqueda de una certeza capaz de sostenerse más allá de todas las diferencias ha fracasado... Kant negó que Dios fuera cognoscible dentro del dominio de la razón pura pero, al mismo tiempo, consideró a Dios, la libertad y la inmortalidad como postulados de la razón práctica sin los cuales era imposible actuar moralmente de forma consistente. ¿No nos obliga la situación actual del mundo a preguntarnos si habrá tenido razón desde un principio?... Tenemos, pues, buenas razones para poner el axioma ilustrado de cabeza y decir que, incluso aquellos que no pueden aceptar a Dios deberían, sin embargo, tratar de vivir veluti si Deus daretur, como si Dios existe» ${ }^{49}$.

¿Qué implica, para el caso del estatus ontológico del feto, nuestra discusión sobre la persona humana entendida teológicamente, así como nuestra opción por la estructura "como si»? Mühling y Gilland estiman que, en sociedades pluralistas donde puede encontrarse una plétora de ideas sobre la persona humana, toda reflexión sobre el estatus ontológico del feto debe seguir un doble camino. Primero, es fundamental aceptar

${ }^{48}$ Richard Rorty afirma, respecto de la obra de Stephen Carter, The Culture of Disbelief: «Las mejores partes de dicha obra, profundamente reflexiva y en muchas ocasiones persuasiva, son aquellas en las que [Carter] exhibe la inconsistencia de nuestro comportamiento, y la hipocresía que se anida en nuestra afirmación de que los creyentes, de alguna forma, no tienen derecho a basar sus posiciones políticas en su fe religiosa, mientras que nosotros, ateos, tenemos todo el derecho a apoyar las nuestras sobre la filosofía ilustrada. La afirmación de que, al hacer esto, estamos apelando a la razón, mientras que los creyentes están siendo irracionales, es una evidente tontería» (Citado en Nicholas Wolterstorff. Religion in the University. New Haven: Yale University Press, 2019, 113-114).

49 Joseph Ratzinger. "Europe in the crisis of cultures". Joseph Ratzinger in Communio, vol. 2, Anthropology and Culture, 198. Grand Rapids: William B. Eerdmans Publishing Company, 2013. 
que en nuestras sociedades pluralistas siempre será posible encontrar una diversidad de nociones sobre la idea de «persona». Por ende: «si... en principio es imposible para los seres humanos decidir, aquí y ahora, si los embriones, las células madre fertilizadas, o incluso los recién nacidos son personas o no, entonces es recomendable actuar bajo un velo de ignorancia». Una vez insertado este velo, Mühling y Gilland ofrecen una conclusión prudencial: «si el embrión... o un recién nacido no fueran tratados como personas, pero fueran ellos mismos personas, esto causaría más daño que si fueran tratados como personas sin serlo» ${ }^{50}$.

La estrategia prudencial de Mühling y Gilland sigue la lógica pascaliana: confrontados con un caso límite que pone en jaque la definición misma de «persona», la respuesta prudencial sugiere tratar al feto como si fuera una persona, puesto que los daños que se siguen de negar al feto dicho estatus, en caso de tratarse, de hecho, de una persona, implican evidentemente la violación de los derechos fundamentales de un ser humano.

La estrategia prudencial basada en la estructura "como si» puede justificarse, finalmente, no solamente en términos pragmáticos - como resultado de una operación mental que estima el valor esperado de determinada decisión- sino como actitud frente al misterio. Gabriel Marcel distingue entre "problema» $\mathrm{y}$ «misterio»: mientras el primero se encuentra completamente "frente a mí», el misterio "es algo dentro del cual yo mismo me encuentro cautivo, y cuya esencia, por lo tanto, no está completamente frente a mí. Es como si aquí la distinción entre en mí y frente a mí perdiera su significado ${ }^{51}$. La preocupación de Marcel respecto de la perenne tentación de reducir el misterio al problema no es sino una

50 Mühling y Gilland. "Which Relationality?”, 485. Los autores están reaccionando contra el controversial y ampliamente criticado artículo de Alberto Giubilini y Francesca Minerva, quienes afirman que «cuando ocurren ciertas circunstancias luego del nacimiento, que habrían sido suficientes para justificar el aborto, lo que llamamos aborto post-nacimiento debería ser permisible... proponemos llamar a esta práctica "aborto post-nacimiento" en lugar de "infanticidio", a fin de enfatizar que el estatus moral del individuo asesinado es comparable con el del feto... y no con el de un niño» (Alberto Giubilini, y Francesca Minerva. "After-birth abortion: why should the baby live?”. Journal of Medical Ethics 39 (2013): 261-262). Destaca en la postura de Giubilini y Minerva la absoluta inatención a la pregunta sobre el feto, lo cual contrasta con la tácita e injustificable presuposición de la licitud del aborto como res iudicata. La posición de ambos autores es paradigmática de la irresponsabilidad intelectual que denunciamos en este artículo.

51 Gabriel Marcel. Being and Having. Glasgow: Dacre Press, 1949, 100. 
reformulación del problema de reducir un «quién» al estatus de «qué» que vimos con Arendt. Para Marcel el error de dicha reducción se explica porque «lo Misterioso y lo Ontológico son idénticos» ${ }^{52}$.

A la luz del pensamiento de Marcel podemos decir que, contrario a nuestra actitud frente a un problema - el cual podemos analizar, dividir en sus partes constitutivas, reorganizar y someter a experimentación a fin de generar, en terminología cartesiana, conocimiento claro y distinto y, a partir de él, progreso - el misterio no puede ser reducido a simple cosa cuya observación es ajena a mí. El misterio me interpela en lo profundo, y por ende se resiste a cualquier objetivación. Frente a él la razón se detiene, presa de admiración frente a lo incomprensible que, no obstante, se anida precisamente en lo más íntimo de mi ser. Es ahí, precisamente, en el reconocimiento de que, frente al misterio - ya sea el problema del mal, del libre albedrío o de la personalidad del feto- no puedo pretender un "progreso» a la manera de las ciencias exactas, sino simplemente la contemplación de un problema contra el cual no puedo cobrar distancia, donde la frase de Agustín resuena contundentemente: «Quid tam tuum quam tu, quid tam non tuum quam tu», ¿qué te pertenece más que tu propio ser, y qué te pertenece menos que tu propio ser?

Alumbrado por el existencialismo de Marcel, el aborto aparece ya no como problema ético, como pregunta que exige mayor investigación y sofisticación técnica, sino como misterio que pone en jaque la certeza del propio yo, haciendo manifiesta la infranqueable tensión que se anida en el espíritu humano, que se conoce a sí mismo sin dejar nunca de ser un misterio para sí mismo; que postula argumentos que abren posibilidades al pensamiento sin dejar de reconocer que a la luz que se cuela por toda ventana le corresponde, ineluctablemente, una zona de obscuridad. Pensar al feto como si fuera persona no implica renunciar al escrutinio del término, buscando cada vez mejores aproximaciones, sino reconocer que toda aproximación será inevitablemente incompleta y metafísica; no significa renunciar a los datos de la ciencia, al contrario, exige incorporarlos en una reflexión más amplia sobre los límites de la razón humana; no traiciona una voluntad de imponer determinada concepción metafísica por la puerta trasera, sino el acto prudencial de una razón que ha sido confrontada con sus límites y que, frente al misterio, opta por el respeto de lo que parece estar ahí y que, de estar, exige ser tratado como

52 Ibid., 101. 
fin en sí mismo, como repositorio de una dignidad que acarrea derechos y libertades inalienables.

\section{REFERENCIAS}

Abbey, Ruth. Charles Taylor. Teddington: Acumen, 2000.

Adorno, Theodor, y Max Horkheimer. Dialéctica de la Ilustración. 8. a ed. Madrid: Trotta, 2006.

Agamben, Giorgio. Homo Sacer: Sovereign Power and Bare Life. Stanford: Stanford University Press, 1998. DOI: https://doi. org/10.1515/9780804764025

Agamben, Giorgio. Remnant of Auschwitz. The Witness and the Archive. New York: Zone Books, 1999.

Agamben, Giorgio. State of Exception. Chicago: The University of Chicago Press, 2005.

Agamben, Giorgio. The Time that Remains. Stanford: Stanford University Press, 2005.

Agustín de Hipona. The City of God Against the Pagans. Cambridge: Cambridge University Press, 2014.

Appiah, Kwame A. As If. Idealization and Ideas. Cambridge: Harvard University Press, 2017.

Aquino, Tomás de. Summa Contra Gentiles. Disponible en http://santotomasdeaquino.verboencarnado.net/capitulo-lxxxix-solucionde-las-objeciones-anteriores/

Aquino, Tomás de. Summa Theologiae. Disponible en http://www.newadvent.org/summa/

Arendt, Hanna. La Condición Humana. Barcelona: Paidós, 2016.

Beauvoir, Simone de. El Segundo Sexo. México: Penguin Random House, 2012.

Bellieni, Carlo V. "New Insights into Fetal Pain". Seminars in Fetal and Neofetal Medicine 24 (2019): 1-5. DOI: https://doi.org/10.1016/j. siny.2019.04.001

Bergner, Raymond M. "What is a Person? What is the Self? Formulations for a Science of Psychology". Journal of Theoretical and Philosophical Psychology 37, n. ${ }^{\circ} 2$ (2017): 77-90. DOI: https://doi.apa.org/doi/10.1037/ teo0000057 
Blakely, Jason. Alasdair MacIntyre, Charles Taylor, and the Demise of Naturalism. Reunifying Political Theory and Social Science. Notre Dame: University of Notre Dame Press, 2016.

Camosy, Charles C. "Common Ground on Surgical Abortion? - Engaging Peter Singer on the Moral Status of Potential Persons". Journal of Medicine and Philosophy 33 (2009): 577-593.

Collin, P. H. Dictionary of Medicine. New York: Routledge, 2014.

Concilio Vaticano II. Gaudium et Spes. Ciudad del Vaticano: Libreria Editrice Vaticana, 1965.

Congregación para la Doctrina de la Fe. Instrucción Donum Vitae. Sobre el Respeto de la Vida Humana Naciente y la Dignidad de la Procreación. Ciudad del Vaticano: Libreria Editrice Vaticana, 1987.

Congregación para la Doctrina de la Fe (CDF). Declaración sobre el Aborto. Ciudad del Vaticano: Libreria Editrice Vaticana, 1974.

Craddock, Joshua J. "Protecting Prenatal Persons: Does the Fourteenth Amendment Prohibit Abortion". Harvard Journal of Law \& Public Policy 40-2 (2017): 539-572.

Dreyfus, Hubert, y Charles Taylor. Retrieving Realism. Cambridge: Harvard University Press, 2015.

Francisco. Evangelii Gaudium. Ciudad del Vaticano: Libreria Editrice Vaticana, 2013.

Gest, Howard. "The discovery of microorganisms by Robert Hooke and Antoni van Leeuwenhoek, fellows of the royal Society". Notes and Records of the Royal Society of London 58, n. ${ }^{\circ} 2$ (2004): 187-201. DOI: https://doi.org/10.1098/rsnr.2004.0055

Giubilini, Alberto, y Francesca Minerva. "After-birth abortion: why should the baby live?". Journal of Medical Ethics 39, n. ${ }^{\circ} 5$ (2013): 261-263. DOI: https://doi.org/10.1136/medethics-2011-100411

Gregory, Brad S. The Unintended Reformation. How a Religious Revolution Secularized Society. Cambridge: The Belknap Press of Harvard University Press, 2012.

Heidegger, Martin. Being and Time. Albany: State University of New York Press, 2010.

Iglesia Católica. Catecismo de la Iglesia Católica. Ciudad del Vaticano: Libreria Editrice Vaticana, 1997.

Jones, David A. "Aquinas as an Advocate of Abortion? The Appeal to 'Delayed Animation' in Contemporary Christian Ethical Debates on the 
Human Embryo". Studies in Christian Ethics 26, n. 1 (2013): 97-124. DOI: https://doi.org/10.1177\%2F0953946812466495

Juan Pablo II. Fides et Ratio. Ciudad del Vaticano: Libreria Editrice Vaticana, 1998.

Juan Pablo II. Evangelium Vitae. Ciudad del Vaticano: Libreria Editrice Vaticana, 1995.

Kértesz, Imre. Sin Destino. Barcelona: Acantilado, 2006.

Last, John M., ed. Dictionary of Public Health. New York: Oxford University Press, 2007.

Levi, Primo. If this is a Man. New York: Orion Press, 1959.

Marcel, Gabriel. Being and Having. Glasgow: Dacre Press, 1949.

Marquis, Don. "Abortion and the Beginning and End of Human Life". Journal of Law, Medicine \& Ethics 34-1 (2006): 16-25.

Mühling, Markus, y David Gilland. "Which Relationality? Whose Personhood? The Christian Understanding of the Person, 'After-Birth Abortion' and Embryonic Stem Cell Research". Studies in Christian Ethics 26, n. ${ }^{\circ} 4$ (2013): 473-486. DOI: https://doi.org/10.1177\%2F0953946813492920

Pascal, Blaise. Pensées and Other Writings. New York: Oxford University Press, 2008.

Pawlowski, Artur. "Miracle baby': Born at 21 weeks, she may be the most premature surviving infant". Today. Noviembre 9, 2017. Disponible en https://www.today.com/health/born-21-weeksshe-may-be-most-premature-surviving-baby-t118610

Ratzinger, Joseph. The Yes of Jesus Christ. Spiritual Exercises in Faith, Hope, and Love. New York: Crossroad, 2018.

Ratzinger, Joseph. "Concerning the notion of the Person in Theology". Joseph Ratzinger in Communio, vol. 2, Anthropology and Culture, editado por David L. Schindler y Nicholas J. Healy, 103-118. Grand Rapids: William B. Eerdmans Publishing Company, 2013.

Ratzinger, Joseph. "Man between reproduction and creation: Theological questions on the origin of human life". Joseph Ratzinger in Communio, vol. 2, Anthropology and Culture, editado por David L. Schindler y Nicholas J. Healy, 70-83. Grand Rapids: William B. Eerdmans Publishing Company, 2013.

Ratzinger, Joseph. "Technological security as a problem of social ethics". Joseph Ratzinger in Communio, vol. 2, Anthropology and Culture, editado por David L. Schindler y Nicholas J. Healy, 42-51. Grand Rapids: William B. Eerdmans Publishing Company, 2013. 
Ratzinger, Joseph. "Truth and Freedom”. Joseph Ratzinger in Communio, vol. 2, Anthropology and Culture, editado por David L. Schindler y Nicholas J. Healy, 147-167. Grand Rapids: William B. Eerdmans Publishing Company, 2013.

Ratzinger, Joseph. "Europe in the crisis of cultures". Joseph Ratzinger in Communio, vol. 2, Anthropology and Culture, editado por David L. Schindler y Nicholas J. Healy, 188-199. Grand Rapids: William B. Eerdmans Publishing Company, 2013.

Ratzinger, Joseph. "Beyond Death". Joseph Ratzinger in Communio, Vol. 2. Anthropology and Culture, editado por David L. Schindler y Nicholas J. Healy, 9-13. Grand Rapids: William B. Eerdmans Publishing Company, 2013.

Ratzinger, Joseph. Introduction to Christianity. San Francisco: Ignatius Press, 2004.

Sartre, Jean Paul. Existentialism is a Humanism. New Haven: Yale University Press, 2007.

Taylor, Charles. The Language Animal. Cambridge: Harvard University Press, 2016.

Taylor, Charles. The Ethics of Authenticity. Cambridge: Harvard University Press, 2003.

Taylor, Charles. "The Politics of Recognition". En Multiculturalism, editado por Amy Gutmann, 25-74. Princeton: Princeton University Press, 1994.

Taylor, Charles. "The Concept of a Person”. En Philosophical Arguments I, 97-114. Cambridge: Cambridge University Press, 1985.

Wolterstorff, Nicholas. Religion in the University. New Haven: Yale University Press, 2019. 